\title{
Overcoming barriers to student participation in research
}

This article was published in the following Dove Press journal:

Advances in Medical Education and Practice

29 September 2015

Number of times this article has been viewed

\author{
Ravina Tanna',* \\ Nikhil Patel',* \\ Sameera Tanna ${ }^{2}$ \\ 'Imperial College School of Medicine, \\ Imperial College London, South \\ Kensington, ${ }^{2}$ King's College London \\ Medical School, King's College \\ London, London Bridge, London, UK \\ *These authors contributed equally to \\ this work
}

\section{Dear editor}

We read with great interest Sheikh et al's study ${ }^{1}$ on factors contributing to lack of interest in research among medical students in Pakistan. As students in London, UK, we agree that there are a number of barriers preventing medical students engaging in research activities, such as underestimating the importance of research and difficulties making contacts with academics in order to undertake a project.

As echoed in Sheikh et al's study, ${ }^{1}$ it is important to understand why such barriers exist in order to be able to change the current culture. From our observations, reasons for this could be that there is a general lack of awareness of the opportunities available, especially in the early stages of medical school. As such, the importance and benefits of research is not realized until later, often when job applications are looming. Furthermore, students do not always feel comfortable approaching senior clinicians to enquire about the prospect of research opportunities. From the cohort of students who do engage in research, some have not seen their hard work acknowledged by the academic community and may therefore feel discouraged from taking part in projects in the future.

At certain universities, it is compulsory to undertake an intercalated BSc as part of medical training. This is an opportunity to explore a branch of medicine on a more scientific level. A research project is a component of each BSc, which allows students to work alongside academics in carrying out a laboratory, clinical, or library-based project with a view to publication in a peer-reviewed journal. A convenience sample of our colleagues described that their intercalated year was very beneficial in terms of acquiring new skills in data interpretation and analysis as well as in structuring a thorough research project with the bonus of being able to publish a paper. Most students, until now, would not have been in a position to conduct such research, and it can be argued that it should occur much earlier in medical school due to its proven benefits.

Having conducted research not only shows appreciation for the academic aspect of a medical career but also makes an application for the foundation program much more competitive. This is even more important with the increase in popularity of the Academic Foundation Programme (in 2015, a total of 2,146 applications were made for only 510 vacancies $^{2}$ ). We strongly feel that exposure to academic medicine needs to occur at an earlier stage in medical schools due to the benefits we described earlier. In order to achieve this, we would encourage faculties to put academia at the forefront of the medical school curriculum through increased flexibility in the timetable and 
also by introducing compulsory, dedicated modules in the early undergraduate years.

\section{Disclosure}

The authors report no conflicts of interest in this communication.

\section{References}

1. Sheikh AS, Sheikh SA, Kaleem A, Wagas A. Factors contributing to lack of interest in research among medical students. Adv Med Educ Pract. 2013;4:237-243.

2. The UK Foundation Programme Office. Foundation programme 2015: Recruitment stats and Facts. Cardiff: The UK Foundation Programme Office; 2015:1-9. 


\section{Authors' Reply}

\section{Ali Sibtain Farooq Sheikh \\ Saman Ali Sheikh}

Acute Medicine Department, Royal Bournemouth Hospital, Bournemouth UK

Correspondence: Ali Sibtain Farooq Sheikh

Acute Medicine Department, Royal Bournemouth Hospital,

Bournemouth BH7 7DW, UK

Tel +4474I7434748

Email asfsheikh@gmail.com

\section{Dear editor}

We appreciate Tanna et al's interpretation and gratitude regarding our article. At this point, we would like to highlight a few key points. It is apparent that a lack of student participation in research activities is prevalent across more than one society. Working for the National Health Service (NHS) UK, Dr Sheikh can relate to his daily observations where medical students are less concerned about research and its future scope. The "barriers" across different medical schools in the UK and other parts of the world can vary. In today's ever-changing world of science, clinicians are constantly in need to update their knowledge for better management of their patients. They research in one way or another. A system of revalidation by the General Medical Council (GMC) is in action to assess competencies gained from time to time. ${ }^{1}$ It nicely reflects upon an individual's success, for which he/she has surely done research, at least on a basic level. Clinical rotations are mandatory in most years of medical schools; however, such a trend does not exist in relation to research activities. Perhaps one rotation in a research setting could give medical students a timely understanding of the process. This could be particularly beneficial for those who wish to pursue a career as a scientist. Institutional support is necessary to formulate the feasibility of such a proposal.Additionally, most international journals accept manuscripts from all ranks of people. This makes it particularly difficult for medical students to compete with experienced researchers in order to get published. In fact, a comparison between the two is not realistic. In contrast, the student British Medical Journal (sBMJ) focuses on only accepting manuscripts from medical students and young doctors. This is very encouraging, yet remains competitive. There is a dire need for more journals that facilitate publication opportunities for medical students. We believe that we have made the first step toward making research more popular among medical students.

\section{Disclosure}

The authors report no conflicts of interest in this communication.

\section{Reference}

1. Registration and licensing: Revalidation [webpage on the Internet]. General Medical Council; 2015. Available from: http://www.gmc-uk. org/doctors/revalidation.asp. Accessed September 8, 2015.

Dove Medical Press encourages responsible, free and frank academic debate. The content of the Advances in Medical Education and Practice 'letters to the editor' section does not necessarily represent the views of Dove Medical Press, its officers, agents, employees, related entities or the Advances in Medical Education and Practice editors. While all reasonable steps have been taken to confirm the content of each letter, Dove Medical Press accepts no liability in respect of the content of any letter, nor is it responsible for the content and accuracy of any letter to the editor.

\section{Publish your work in this journal}

Advances in Medical Education and Practice is an international, peerreviewed, open access journal that aims to present and publish research on Medical Education covering medical, dental, nursing and allied health care professional education. The journal covers undergraduate education, postgraduate training and continuing medical education including emerging trends and innovative models linking education, research, and health care services. The manuscript management system is completely online and includes a very quick and fair peer-review system. Visit http://www.dovepress.com/testimonials.php to read real quotes from published authors. 